\title{
Evaluation of the Clinical Efficacy of Liquid Resuscitation Combined with Ulinastatin in Patients with Sepsis
}

\author{
SHANSHAN SUN, WENHUAN LI ${ }^{1}$, MIAOSHU WANG AND ZHENZHEN CHEN*
}

Department of Critical Care Medicine, 'Department of General Surgery, The First People's Hospital of Wenling, Wenling 317500, Zhejiang Province, China

\section{Sun et al.: Clinical Efficacy of Liquid Resuscitation Combined with Ulinastatin}

\begin{abstract}
We attempts to exam the clinical efficacy of fluid resuscitation combined with ulinastatin in treatment of patients with sepsis and to analyze the effects of the combination on acute physiology and chronic health evaluation II score, sequential organ failure assessment score, oxygenation index and inflammatory factors. We chose 60 patients with sepsis from July 2020 to July 2021 in the intensive care unit ward of our hospital as the study cohort. Divided them into two groups, one is control group $(n=30)$ and the other is observation group $(n=30)$ randomly. Patients in control group were offered basic treatments such as antibiotics, nutritional support and blood pressure drugs, and were given fluid resuscitation at the same time. After the observation group was treated the same as the control group add ulinastatin injection. Contrast the changes in acute physiology and chronic health evaluation II score, sequential organ failure assessment score, incidence of disseminated intravascular coagulation and multiple organ dysfunction syndrome, changes in oxygenation index, serum creatinine, total bilirubin and inflammatory factors among both groups after treatment, then contrast the mortality and clinical effectiveness of both groups as well. After treatment, observation groups acute physiology and chronic health evaluation II score, sequential organ failure assessment score, organ injury, serum creatinine, total bilirubin, inflammation indicators (C-reactive protein, procalcitonin, interleukin-6) were remarkably lowered $(\mathbf{p}<\mathbf{0 . 0 5})$. Contrast the clinical effective rate of both groups, observation group efficiency was higher $(p<0.05)$, but disseminated intravascular coagulation, multiple organ dysfunction syndrome and mortality incidence in observation group was lower $(\mathbf{p}<\mathbf{0 . 0 5})$, with statistical differences. Liquid resuscitation combined with ulinastatin has important clinical significance in the treatment of sepsis, improving the effective rate of clinical treatment, reducing the incidence of disseminated intravascular coagulation, multiple organ dysfunction syndrome and mortality in the group, improving inflammatory factors, organ dysfunction parameters and other indicators, which are worth of clinical promotion.
\end{abstract}

Key words: Fluid resuscitation, ulinastatin, acute physiology and chronic health evaluation II score, sequential organ failure assessment score

Sepsis defines the whole body dysfunction caused by the over activation of the body's inflammatory reaction to infection. Its incidence is increasing every year worldwide $^{[1]}$. Severe sepsis and septic shock are main causes of death in Intensive Care Unit (ICU). Therefore, the treatment of sepsis is continuously improved. Although some progress has been made, sepsis is still a big challenge for clinicians ${ }^{[2]}$. Sepsis nosogenesis is complicated, it is believed that it is triggered by Pathogen-Associated Molecular Patterns (PAMPs) and host immune cell pattern recognition receptor interactions ${ }^{[3]}$. It triggers a series of proinflammatory results. Sepsis is the result of excessive activation of the inflammatory response. During systemic inflammation, it is the secretion and release of intermediates. The intermediates are mainly Serine Protease (hereinafter referred as to SP), including trypsin, thrombin, chymotrypsin, kallikrein, plasmin, neutrophil elastase, cathepsin, neutrophil protease 3, coagulation factors IXa, Xa, XIa and XIIa ${ }^{[4]}$, which are characterized by the pro-inflammatory cytokines such as Interleukin (IL)-1, IL-6 and Tumor Necrosis Factor-alpha (TNF- $\alpha$ ) over secretion. Therefore, mediating the above cytokines release or clearance may provide sepsis cure potential targets ${ }^{[5]}$. Ulinastatin is a kind of SP inhibitor that exists in human blood and urine. It is a kind of acid glycoprotein (molecular weight $30 \mathrm{kDa}$ ) and also Kunitz type SP inhibitor. It consists of 143 amino acid residues, including two Kunitz type domain.

*Address for correspondence

E-mail: 2151052082@email.szu.edu.cn 
Studies on animals have proved ulinastatin is effective on anti-inflammatory and also clarified the potential advantages of treating multiple organ dysfunction caused by sepsis. Ulinastatin regulates the function and quantity of Regulatory T-cell (Treg) through the Toll-Like Receptor 4 (TLR4)/Nuclear Factor Kappa light chain enhancer of activated B cells (NF- $\mathrm{BB}$ ) signaling pathway, thereby improving the damage of inflammatory factors to organs ${ }^{[6]}$.

In the first few hours of severe sepsis, venous dilation and fluid leakage from the vascular space into the tissues will cause early blood volume hypovolemia ${ }^{[7]}$.

Ventricular dysfunction and depletion of dilated volume of arterioles lead to overall perfusion and impaired organ function. Hypovolemia treatment is very important in the beginning of severe sepsis cure ${ }^{[8]}$. Nevertheless, under the condition the patient receives enough fluid, cardiac output or overall perfusion will not be enhanced, but redundant fluid possibly enhance interstitial edema, meanwhile cause microvascular dysfunction. The current fluid management practices for patients with sepsis are adequate. At present, an ample early stage fluid resuscitation seems to be a kind of fluid management standard in sepsis patients ${ }^{[9]}$. Therefore, we determined to start this study to examine the clinical value of ulinastatin combined with fluid resuscitation in patients with sepsis.

\section{MATERIALS AND METHODS}

\section{General information:}

We chose 60 sepsis patients from July 2020 to July 2021 in the ICU ward from our hospital and then divided them into two separate groups, that is observation group and control group, each group possessed 30 cases. All patients admitted to the ICU received enrollment screening. Two senior intensive care physicians who had over 1 decade of clinical experience in ICU reviewed medical record to ensure that each patient meets the conditions for enrollment. Both groups general information were listed in Table 1. Medical Ethics Committee of our hospital admitted this study.

Inclusion criteria: Patients with sepsis on the $1^{\text {st }} \mathrm{d}$ of entering the ICU were included in the study, being up to the diagnostic standard of "Chinese Guidelines for Emergency Treatment of Sepsis/Toxic Shock" ${ }^{[10]}$ and all patients in the group obtained informed consent for treatment.

Exclusion criteria: Pregnant women; patients who are 18 y old or younger; patients who has ulinastatin usage contraindications or drug allergy; patients who has a history of epilepsy, myasthenia gravis, alcoholism, heavy smoking ( $>40$ cigarettes per day), drug addiction, sepsis; patients who have a record of being treated for more than $3 \mathrm{~d}$ in other hospital after arriving into our hospital; patients with cardiopulmonary dysfunction or a history of malignant tumor.

\section{Methods:}

Treatment method: The control group was given basic treatments such as antibiotics, nutritional support and blood pressure drugs, and fluid resuscitation were given at the same time. After treating in the same way as the control group, the observation group was treated with another ulinastatin injection. Each time 200000 units dissolved in $250 \mathrm{ml} 5 \%$ glucose injection were injected intravenously for 1 to $2 \mathrm{~h}, 3$ times a day.

\section{Observation index:}

Demographic data of both groups, such as age and gender were considered. All admitted patients used Acute Physiology and Chronic Health Evaluation II (APACHE II) score and Sequential Organ Failure Assessment (SOFA) score to evaluate the severity of the disease. We recorded multiple APACHE II and SOFA scores within $24 \mathrm{~h}$ after admission to ICU, later treatment for $3 \mathrm{~d}$ and then treatment for $7 \mathrm{~d}$. If more than one score value is calculated, the study uses the highest score value.

Record the results of experimental examinations on the day of admission, d 3 and d 7, for example, C-Reactive Protein (CRP), IL-6, Procalcitonin (PCT), Oxygenation Index (OI), Serum Creatinine (SCr), Total Bilirubin (TBIL).

Clinical effective rate, which means clinical symptoms or signs disappeared or improved after $3 \mathrm{w}$ of treatment. The clinical efficacy evaluation indicators are clinical symptoms and signs; makers of inflammatory, such as CRP, PCT or IL-6 levels. Remarkably effective: after treatment, the two evaluation indicators are reduced to normal; effective: after treatment, the two evaluation indicators have been improved to a certain extent; Invalidity is one of the following situations: Clinical symptoms or signs deteriorate or persist during treatment and need to be increased other treatments; Death of sepsis after $3 \mathrm{~d}$ of treatment; Complications related to sepsis, such as Disseminated Intravascular Coagulation (DIC) or Multiple Organ Dysfunction Syndrome (MODS). After $30 \mathrm{~d}$ of treatment, sepsis complicated with DIC, MODS and death are compared between the two groups. 


\section{Statistical methods:}

We adopt Statistical Package for the Social Sciences (SPSS) 26.0 to analyze the data, use $n \%$ to express technical data and use $\chi^{2}$ test. Use mean \pm Standard Deviation (SD) to indicate measurement data that accord with normal distribution and homogeneity of variance, compare both groups by independent sample $\mathrm{t}$ test and before and after treatment within the same group comparison was expressed by paired t test. Use median and interquartile range to show data that did not accord with normal distribution; adopt Wilcoxon rank sum test to examine groups comparison, $\mathrm{p}<0.05$ was supported to possess statistical significance.

\section{RESULTS AND DISCUSSION}

Baseline data of both groups before treatment were compared. Both groups have no significant difference in terms of age, gender, underlying diseases, etc., and there was no statistical significance $(\mathrm{p}>0.05)$, both groups possessed comparability (Table 1).

APACHII score and SOFA score of both groups before and after treatment were compared. Both groups were of no remarkable difference in APACHII score and SOFA score before treatment and there was no statistical difference $(\mathrm{p}>0.05)$. In the $3^{\text {rd }}$ and $7^{\text {th }} \mathrm{d}$ after treatment, both groups APACHII scores and SOFA scores were remarkably lower than those before treatment, but observation group dropped more than the other, with significant differences $(p<0.05)$, which was statistically significant, Table 2.
Changes in related parameters of organ dysfunction of both groups before and after treatment were compared. Before treatment, OI, Scr and TBIL levels in both groups were of no significant differences, so it possesses no statistical significance $(\mathrm{p}>0.05) ; 3^{\text {rd }}$ and $7^{\text {th }} \mathrm{d}$ after treatment, contrast both groups OI, Scr and TBIL, observation group had a greater downward trend than the control group, with significant differences and statistical significance $(\mathrm{p}<0.05)$ (Table 3$)$.

Inflammatory indexes (PCT, IL-6, CRP) of both groups before and after treatment were compared. Before treatment, PCT, IL-6 and CRP levels were of no significant differences, thus it possesses no statistical significance $(\mathrm{p}>0.05) ; 3^{\text {rd }}$ and $7^{\text {th }} \mathrm{d}$ after treatment, contrast both groups PCT, IL-6 and CRP, observation group had a greater downward trend than the other, it possesses significant differences and statistical significance $(p<0.05)$ (Table 4).

The incidence of MODS, DIC and $30 \mathrm{~d}$ mortality after treatment between the two groups were compared. After $30 \mathrm{~d}$ of treatment, there was 1 death in observation group, 2 cases of DIC and 8 cases MODS in observation group, 6 cases of death in control group, 8 cases of DIC and 10 cases MODS in control group. Both groups were of no significant differences $(\mathrm{p}<0.05)$ (Table 5).

Clinical efficacy of both groups after treatment was compared. Total clinical effective rate of observation group was remarkably higher than the other $(p<0.05)$ Table 6.

TABLE 1: COMPARISON OF GENERAL INFORMATION OF BOTH GROUPS

\begin{tabular}{lcccc}
\hline & $\begin{array}{c}\text { Observation group } \\
(\mathrm{n}=30)\end{array}$ & Control group $(\mathrm{n}=30)$ & $\mathrm{t} / \chi^{2}$ & $\mathrm{p}$ \\
\hline Age & $59.4 \pm 12.22$ & $58.93 \pm 10.84$ & 0.06 & 0.94 \\
Gender (female) & $18(60 \%)$ & $17(58.3 \%)$ & 0.07 & 0.79 \\
Complications & & & & \\
Hypertension & $8(26.7 \%)$ & $7(23.3 \%)$ & 0.09 & 0.76 \\
Diabetes & $3(10.0 \%)$ & $4(13.3 \%)$ & 0.16 & 0.68 \\
Other & $3(10.0 \%)$ & $2(6.7 \%)$ & 0.22 & 0.64 \\
\hline
\end{tabular}

TABLE 2: COMPARISON OF APACHII SCORE AND SOFA SCORE OF BOTH GROUPS BEFORE AND AFTER TREATMENT

\begin{tabular}{|c|c|c|c|c|c|c|c|}
\hline \multirow[b]{2}{*}{ Grouping } & \multirow{2}{*}{$\begin{array}{c}\text { Quantity of } \\
\text { cases }\end{array}$} & \multicolumn{3}{|c|}{ APACHE-II scores } & \multicolumn{3}{|c|}{ SOFA scores } \\
\hline & & $\begin{array}{c}\text { Before } \\
\text { treatment }\end{array}$ & $\begin{array}{l}3 \mathrm{~d} \text { after } \\
\text { treatment }\end{array}$ & $\begin{array}{l}7 \mathrm{~d} \text { after } \\
\text { treatment }\end{array}$ & Before cure & $\begin{array}{l}3 \mathrm{~d} \text { after } \\
\text { treatment }\end{array}$ & $\begin{array}{l}7 \mathrm{~d} \text { after } \\
\text { treatment }\end{array}$ \\
\hline $\begin{array}{l}\text { Observation } \\
\text { group }\end{array}$ & 30 & $29.1 \pm 9.5$ & $24.33 \pm 2.98$ & $18.8 \pm 2.67$ & $14.93 \pm 3.28$ & $11.23 \pm 2.89$ & $7.03 \pm 1.25$ \\
\hline Control group & 30 & $30.13 \pm 10.18$ & $27.4 \pm 6.50$ & $23 . .63 \pm 2.70$ & $14.91 \pm 4.40$ & $13.36 \pm 3.77$ & $10.2 \pm 2.95$ \\
\hline $\mathrm{t}$ & & -0.14 & -2.37 & -7.30 & -0.02 & -2.45 & -5.41 \\
\hline$p$ value & & 0.68 & 0.02 & 0.000 & 0.97 & 0.01 & 0.000 \\
\hline
\end{tabular}


TABLE 3: COMPARISON OF CHANGES IN RELATED PARAMETERS OF ORGAN DYSFUNCTION BEFORE AND AFTER TREATMENT IN THE TWO GROUPS

\begin{tabular}{|c|c|c|c|c|c|c|c|c|c|c|}
\hline \multirow[b]{2}{*}{ Group } & \multirow{2}{*}{$\begin{array}{l}\text { Number } \\
\text { of cases }\end{array}$} & \multicolumn{3}{|c|}{ OI (mmHg) } & \multicolumn{3}{|c|}{$\mathrm{Scr}(\mu \mathrm{mol} / \mathrm{l})$} & \multicolumn{3}{|c|}{ TTBIL $(\mu \mathrm{mol} / \mathrm{l})$} \\
\hline & & $\begin{array}{c}\text { Before } \\
\text { treatment }\end{array}$ & $\begin{array}{c}\text { After } 3 \mathrm{~d} \\
\text { treatment }\end{array}$ & $\begin{array}{c}\text { After } 7 \text { d } \\
\text { treatment }\end{array}$ & $\begin{array}{c}\text { Before } \\
\text { treatment }\end{array}$ & $\begin{array}{l}\text { After } 3 \mathrm{~d} \\
\text { treatment }\end{array}$ & $\begin{array}{c}\text { After } 7 \mathrm{~d} \\
\text { treatment }\end{array}$ & $\begin{array}{c}\text { Before } \\
\text { treatment }\end{array}$ & $\begin{array}{c}\text { After } 3 \mathrm{~d} \\
\text { treatment }\end{array}$ & $\begin{array}{c}\text { After } 7 \mathrm{~d} \\
\text { treatment }\end{array}$ \\
\hline $\begin{array}{l}\text { Control } \\
\text { group }\end{array}$ & 30 & $260.2 \pm 57.3$ & $323.33 \pm 37.90$ & $384.8 \pm 43.8$ & $234.6 \pm 91.4$ & $138.5 \pm 61.8$ & $87.5 \pm 32.5$ & $51.03 \pm 12.5$ & $33.05 \pm 5.08$ & $21.0 \pm 3.17$ \\
\hline $\begin{array}{l}\text { Observation } \\
\text { group }\end{array}$ & 30 & $261.3 \pm 51.8$ & $287.3 \pm 27.33$ & $320.4 \pm 24.70$ & $232.3 \pm 88.6$ & $170.5 \pm 57.7$ & $133.2 \pm 10.6$ & $51.11 \pm 11.89$ & $41.03 \pm 5.89$ & $24.6 \pm 4.17$ \\
\hline $\mathrm{t}$ & & -0.07 & 3.70 & 7.01 & -0.02 & -2.13 & -7.33 & -0.02 & -5.80 & -2.69 \\
\hline$p$ value & & 0.97 & 0.005 & 0.000 & 0.97 & 0.04 & 0.000 & 0.95 & 0.000 & 0.009 \\
\hline
\end{tabular}

TABLE 4: COMPARISON OF BOTH GROUPS PCT, IL-6, CRP BEFORE AND AFTER TREATMENT

\begin{tabular}{|c|c|c|c|c|c|c|c|c|c|c|}
\hline \multirow[b]{2}{*}{ Group } & \multirow{2}{*}{$\begin{array}{l}\text { Number } \\
\text { of cases }\end{array}$} & \multicolumn{3}{|c|}{ PCT $(\mu \mathrm{g} / \mathrm{l})$} & \multicolumn{3}{|c|}{ IL-6 (pg/ml) } & \multicolumn{3}{|c|}{ CRP (mg/l) } \\
\hline & & $\begin{array}{c}\text { Before } \\
\text { treatment }\end{array}$ & $\begin{array}{l}\text { After } 3 \mathrm{~d} \\
\text { treatment }\end{array}$ & $\begin{array}{c}\text { After } 7 \mathrm{~d} \\
\text { treatment }\end{array}$ & $\begin{array}{c}\text { Before } \\
\text { treatment }\end{array}$ & $\begin{array}{l}\text { After } 3 \mathrm{~d} \\
\text { treatment }\end{array}$ & $\begin{array}{c}\text { After } 7 \mathrm{~d} \\
\text { treatment }\end{array}$ & $\begin{array}{c}\text { Before } \\
\text { treatment }\end{array}$ & $\begin{array}{c}\text { After } 3 \mathrm{~d} \\
\text { treatment }\end{array}$ & $\begin{array}{c}\text { After } 7 \mathrm{~d} \\
\text { treatment }\end{array}$ \\
\hline $\begin{array}{l}\text { Observation } \\
\text { group }\end{array}$ & 30 & $19.3 \pm 4.17$ & $8.06 \pm 3.72$ & $1.46 \pm 0.82$ & $94.23 \pm 30.4$ & $62.3 \pm 17.5$ & $29.95 \pm 7.33$ & $85.66 \pm 20.2$ & $56.33 \pm 21.3$ & $21.2 \pm 11.7$ \\
\hline $\begin{array}{l}\text { Control } \\
\text { group }\end{array}$ & 30 & $19.2 \pm 4.33$ & $11.8 \pm 3.21$ & $2.42 \pm 0.94$ & $95.4 \pm 31.03$ & $80.1 \pm 23.1$ & $45.2 \pm 12.93$ & $85.36 \pm 21.3$ & $73.7 \pm 17.73$ & $42.06 \pm 10.2$ \\
\hline $\mathrm{t}$ & & 0.09 & -3.61 & -4.21 & -0.14 & -3.666 & -5.66 & -0.02 & -3.43 & -7.37 \\
\hline$p$ value & & 0.93 & 0.006 & 0.007 & 0.88 & 0.005 & 0 & 0.95 & 0.001 & 0 \\
\hline
\end{tabular}

TABLE 5: COMPARISON OF THE BOTH GROUPS INCIDENCE OF MODS, DIC AND 30 D MORTALITY AFTER TREATMENT

\begin{tabular}{lcccc}
\hline & $\begin{array}{c}\text { Observation group } \\
(\mathbf{n}=30)\end{array}$ & $\begin{array}{c}\text { Control group } \\
(\mathbf{n}=30)\end{array}$ & $\mathrm{p}$ \\
\hline DIC & $2(6.7 \%)$ & $8(26.7 \%)$ & 4.32 & 0.03 \\
MODS & $3(10.0 \%)$ & $10(33.3 \%)$ & 4.81 & 0.02 \\
$28 \mathrm{~d}$ mortality & $1(3.3 \%)$ & $6(20.0 \%)$ & 4.04 & 0.04 \\
\hline
\end{tabular}

TABLE 6: COMPARISON OF BOTH GROUPS CLINICAL EFFICACY AFTER TREATMENT

\begin{tabular}{|c|c|c|c|c|}
\hline & Markedly effective & Efficient & Invalid & Total effective rate \\
\hline Observation group & $20(66.7 \%)$ & $9(30 \%)$ & $1(3.3 \%)$ & $29(96.7 \%)$ \\
\hline Control group & $15(50 \%)$ & $8(26.7 \%)$ & 7 (23.3\%) & $23(76.7 \%)$ \\
\hline$\chi^{2}$ & & & & 5.19 \\
\hline $\mathrm{p}$ & & & & 0.03 \\
\hline
\end{tabular}

Sepsis is the inability of the body's immune response to return to homeostasis induced by invading pathogens, which ultimately leads to pathological signs, which has the characteristics of continuous excessive inflammation and immunosuppression. Sepsis patient's condition develops swiftly. Although we treat well and monitor strictly, both sepsis morbidity and mortality remains high, it is a typical problem in global medical field ${ }^{[11]}$. At the early stage of sepsis, it is very important to reduce mortality by timely and targeted treatment. Most experts believe that tissue and organ damage which is caused by excessive inflammation results in sepsis. However, more and more studies have proved that sepsis had a very complicated physiological pathology process, including various aspects such as inflammation, immune and coagulation dysfunction, as well as various changes in cell function, metabolism and microcirculation ${ }^{[12]}$.

This study shows that fluid resuscitation combined with ulinastatin have something to do with reducing mortality in sepsis patients after $30 \mathrm{~d}$ treatment. It has been reported that among 122 sepsis patients, there were one or more organ failure ${ }^{[13]}$ treated with ulinastatin. It 
was found that in $28 \mathrm{~d}$ all-cause mortality in ulinastatin group was $7.3 \%$ (4 deaths), while that in control group was $20.3 \%$ (12 deaths) $(\mathrm{p}=0.045)$, which was the same as the results of our research. However, the results of other studies are different from our observations. Some studies, after adjusting for disease severity and other confounding factors, found that there was no relationship between ulinastatin treatment and $30 \mathrm{~d}$ mortality (Odds Ratio (OR): 1.22; $95 \%$ Confidence Interval (CI): 0.54-2.79 $)^{[14]}$. These differences may reflect that the patients who took part in this study were younger than the patients evaluated in our study. Our research proves that ulinastatin treatment method may possibly have effect on helping ICU patients to get through the critical stage of sepsis.

Ulinastatin benefits in improving inflammation in sepsis. For example, it is reported that ulinastatin regulates the number and function of Tregs by TLR4/NF- $\mathrm{kB}$ signaling pathway to reduce inflammatory damage. Our clinical studies did not evaluate these biomarkers ${ }^{[15]}$. Nonetheless, we checked the changes in inflammatory biomarkers (such as CRP and PCT) and found that the biomarkers levels in treatment group decreased more compared with control group. Therefore, our research results prove that ulinastatin has anti-inflammatory effect. Studies have also found that ulinastatin combined with Xuebijing treatment can reduce mortality and shorten the length of ICU stay ${ }^{[16]}$. Although there is no difference on mortality results together with our study, our study did not report the effect of ulinastatin on the length of ICU stay. Ulinastatin combined with other inflammatory modifiers (such as thymosin $\alpha 1$ ) has proved that enhancing cell-mediated immunity can restore immune function, which is expected to reduce mortality ${ }^{[17]}$.

The hemodynamic changes of sepsis are extremely complex, including insufficient volume, decreased myocardial function and changes in microvascular flow. According to reports, patients with preserved ventricular function might become worse as severely decreased contractility ${ }^{[18]}$. In addition, as the volume load increases, patients may experience severe tissue edema, which affects tissue oxygenation. During the course of treatment, the hemodynamic characteristics of each patient required dynamic monitoring and intervention therapy might be required according to the changes in these characteristics ${ }^{[19]}$. Early fluid resuscitation mainly includes Central Venous Pressure (CVP) reaching $>8 \mathrm{~cm}$ water $\left(\mathrm{H}_{2} \mathrm{O}\right)$ (or $12 \mathrm{~cm} \mathrm{H}_{2} \mathrm{O}$ when using a ventilator). This study confirms that early fluid resuscitation has important clinical value for sepsis ${ }^{[20]}$.

There are several limitations in our research. First, retrospective design may lead to selection bias. There may be confounding factors that cannot be measured because patients receiving ulinastatin differ from the control group in many ways. For example, we cannot rule out confounding factors for indications, because attending doctor could determine the use of ulinastatin on their own. Adopting multivariate regression model is a standard method to adjust these confounding factors, but we did not use. We still have other limitation that we lacked comparison with other anti-inflammatory drugs, such as Xuebijing or Thymosin $\alpha_{1}$, so we cannot determine the synergistic effect of these drugs with ulinastatin. In summary, our research has found that fluid resuscitation combined with ulinastatin has important clinical significance in the treatment of sepsis, improving the effective rate of clinical treatment, reducing the incidence of DIC, MODS and mortality, and improving inflammatory factors and organ dysfunction parameters and other indicators, which is worthy of clinical promotion.

\section{Conflicts of interest:}

The authors declared no conflict of interest.

\section{REFERENCES}

1. Huang M, Cai S, Su J. The pathogenesis of sepsis and potential therapeutic targets. Int J Mol Sci 2019;20(21):5376.

2. Salomão R, Ferreira BL, Salomão MC, Santos SS, Azevedo LC, Brunialti MK. Sepsis: evolving concepts and challenges. Braz J Med Biol Res 2019;52(4): e8595.

3. Napolitano LM. Sepsis 2018: definitions and guideline changes. Surg Infect 2018;19(2):117-25.

4. Woznica EA, Inglot M, Woźnica RK, Lysenko L. Liver dysfunction in sepsis. Adv Clin Exp Med 2018;27(4):547-51.

5. Van Der PT, van de VF, Scicluna BP, Netea MG. The immunopathology of sepsis and potential therapeutic targets. Nat Rev Immunol 2017;17(7):407-20.

6. Wang J, Zhou J, Bai S. Combination of glutamine and ulinastatin treatments greatly improves sepsis outcomes. J Inflamm Res 2020;13:109-15.

7. Rello J, Valenzuela-Sánchez F, Ruiz-Rodriguez M, Moyano S. Sepsis: A review of advances in management. Adv Ther 2017;34(11):2393-411.

8. Zhiyun Z, Ling L, Jilu Y. Significance of early central venous blood oxygen saturation in patients with severe sepsis and septic shock. J Mod Med Health 2008;20(24).

9. Font MD, Thyagarajan B, Khanna AK. Sepsis and Septic Shock-Basics of diagnosis, pathophysiology and clinical decision making. Med Clin North Am 2020;104(4):573-85.

10. Emergency physicians branch of Chinese Medical Association, shock and sepsis committee of chinese research hospital association. Guidelines for emergency treatment of sepsis/septic shock in China (2018). Infect Inflamm Repair 2019;1(20). 
11. Martin-Loeches I, Garnacho-Montero J, Nseir S. Focus on infection and sepsis 2017. Intensive Care Med 2017;43(6):8679.

12. Wang YC, Weng GP, Liu JP, Li L, Cheng QH. Elevated serum IL-37 concentrations in patients with sepsis. Medicine 2019;98(10).

13. Jiang $\mathrm{W}, \mathrm{Yu} \mathrm{X}$, Sun $\mathrm{T}$, Chai $\mathrm{Y}$, Chang $\mathrm{P}$, Chen $\mathrm{Z}$, et al. Adjunctive ulinastatin in sepsis treatment in china (ADJUST study): Study protocol for a randomized controlled trial. Trials 2018;19(1):1-9.

14. Wang H, Liu B, Tang Y, Chang P, Yao L, Huang B, et al. Corrigendum: Improvement of sepsis prognosis by Ulinastatin: A systematic review and meta-analysis of randomized controlled trials. Front Pharmacol 2020;10:1697.

15. Xiao SH, Luo L, Liu XH, Zhou YM, Liu HM, Huang ZF. Curative efficacy and safety of traditional Chinese medicine xuebijing injections combined with ulinastatin for treating sepsis in the Chinese population: A meta-analysis. Medicine 2018;97(23):e10971.

16. Meng C, Qian Y, Zhang WH, Liu Y, Song XC, Liu H, et al. A retrospective study of ulinastatin for the treatment of severe sepsis. Medicine 2020;99(49).
17. Meng F, Du C, Zhang Y, Wang S, Zhou Q, Wu L, et al. Protective effect of rhubarb combined with ulinastatin for patients with sepsis. Medicine 2020;99(7):e18895.

18. Ziwei W. Nursing effect of early fluid resuscitation in patients with sepsis. J Clin Nurs Pract 2020;11(5).

19. Ma Lixia. Current situation and new progress of fluid management in sepsis patients. J Chin Pract Diagn Ther 2016;3(30).

20. Wu X, Hu Z, Yuan H, Chen L, Li Y, Zhao C. Fluid resuscitation and markers of glycocalyx degradation in severe sepsis. Open Med 2017;12(1):409-16.

This is an open access article distributed under the terms of the Creative Commons Attribution-NonCommercial-ShareAlike 3.0 License, which allows others to remix, tweak, and build upon the work non-commercially, as long as the author is credited and the new creations are licensed under the identical terms

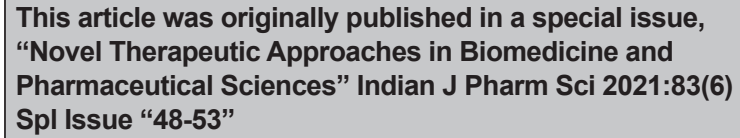

